\title{
Probable new horizons for cholesterol and lipoproteins
}

Authors: Vukovic N. ${ }^{1}$, Milic V. ${ }^{1}$, Dinic L. ${ }^{2}$ Institutes: ${ }^{1}$ Center for Anaesthesiology\& Intensive Care, Clinical Center Nish, ${ }^{2} U$ rology Clinic,Clinical Center Nish, Serbia

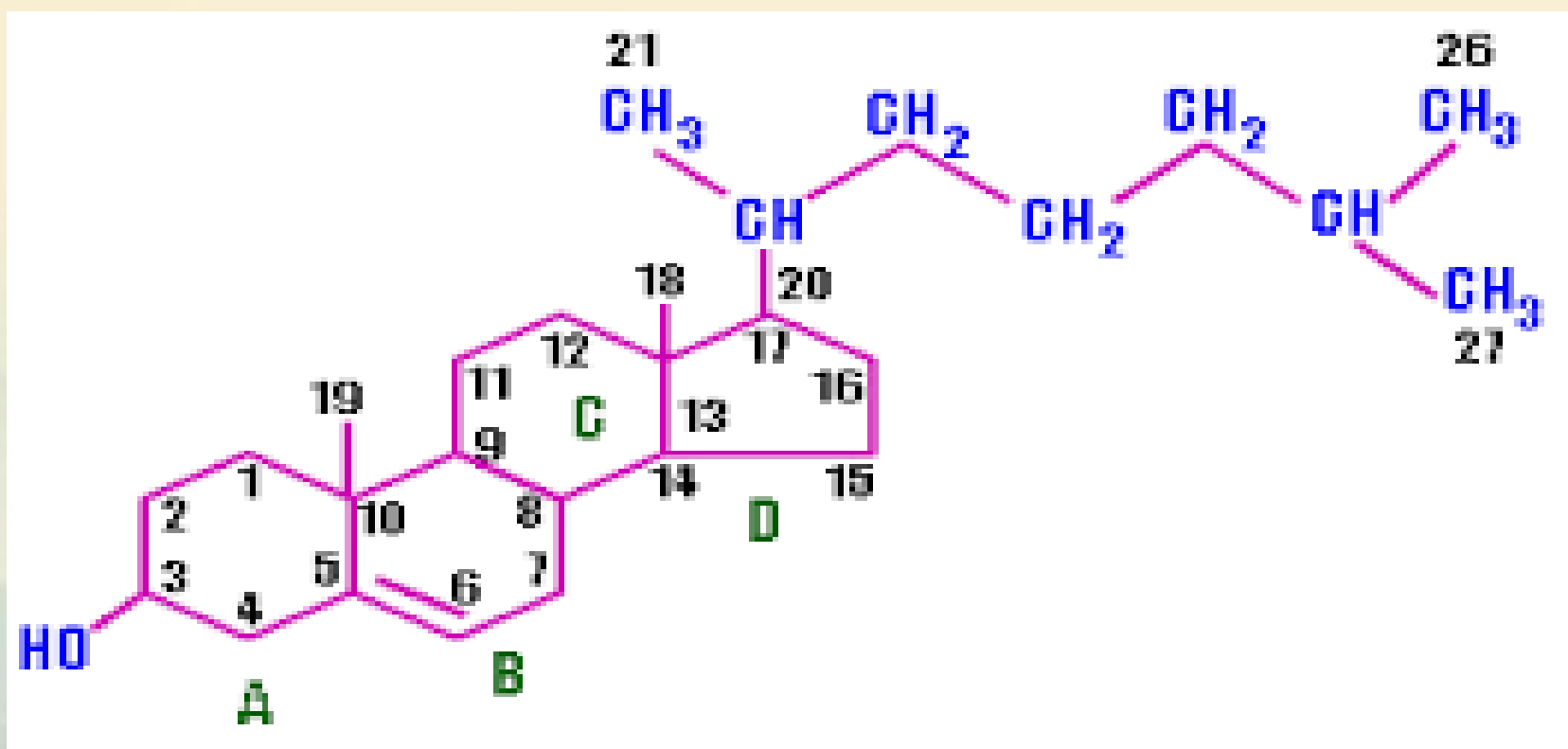

\section{Background and goal of study: Cholesterol} represents the major constituent of cell membranes and it is in relative proportion to phospholipids, which largely determines their physical properties. Total cholesterol, high density lipoprotein (HDL) and low density lipoprotein (LDL), as fractions of total cholesterol, are markers of cardiovascular-disease epidemiologic features, but their role as markers of nutritional status and influence on perioperative complications is yet to be understood.

The goal of the study was to evaluate perioperative levels of total cholesterol, HDL and LDL in patients with different nutritional status and their influence on surgical complication rate.

\section{Materials and methods: A retrospective audit was} carried out from clinical records of patients with radical cystectomy with urinary diversion during 5 years.

According to body mass index, patients were divided in two groups $B M I^{1} \leq 22 \mathrm{~kg} / \mathrm{m}^{2}$ and $B M I^{2}>22 \mathrm{~kg} / \mathrm{m}^{2}$. Total cholesterol, HDL and LDL were measured preoperatively and on the fifth day after operation. Complications were defined as surgical complications that led to relaparatomy. The data was analyzed using Fisher's exact test and Mann-Whitney $U$ test.
Results and discussion; During the study period 42 patients underwent radical cystectomy with urinary diversion. The age of patients in both groups was similar with average of $63,62 \pm 7,97$ years old. There wasn't any statistically significant difference in the type of operation and pathohystology between the groups. There was statistical significance in the postoperative change of total cholesterol and LDL in both groups (Fisher's exact test: $p=0,001$ for cholesterol and $p=0,001$ for LDL). The HDL showed difference perioperatively just in the group of patients with lower BMI $(p=0,001)$. Complications occurred more frequently in the group of patients with lower total cholesterol $(p=0,013 ; p<0,05)$ (Table1). The median LDL cholesterol value was lower in the group of patients with which surgical complications occurred $(\mathrm{Me}=2,75 \mathrm{mmol} / \mathrm{l})$ compared to the patients without complications.

\begin{tabular}{|c|c|c|c|}
\hline \multicolumn{4}{|c|}{$\begin{array}{c}\text { Table 1. Complications frequency in patients with different } \\
\text { preoperative serum cholesterol concentrations }\end{array}$} \\
$\begin{array}{c}\text { Cholesterol } \\
(\mathrm{mmol} / \mathrm{l})\end{array}$ & $\begin{array}{c}\text { No } \\
\text { complications }\end{array}$ & Complications & Total \\
\hline$<3,85$ & $4(28,6)$ & $10(71,4)$ & $14(100,0)$ \\
\hline$\geq 3,85$ & $18(72,0)$ & $7(28,0)$ & $25(100,0)$ \\
\hline Total & $22(56,4)$ & $17(43,6)$ & $39(100,0)$ \\
\hline Min-max & $2,83-7,74$ & $1,90-5,32$ & $1,90-7,74$ \\
\hline Xsr. \pm SD & $4,63 \pm 1,08$ & $3,70 \pm 1,12$ & $4,22 \pm 1,18$ \\
\hline Me & 4,69 & 3,70 & 4,50 \\
\hline $25-75 . p e r c$. & $3,9675-5,015$ & $2,76-4,75$ & $3,20-4,97$ \\
\hline
\end{tabular}

Conclusion: Total cholesterol may be important biochemical parameter for nutrition and complication assesment. Further investigation should include more sensitive nutritional parameters to compare with cholesterol and lipoproteins.

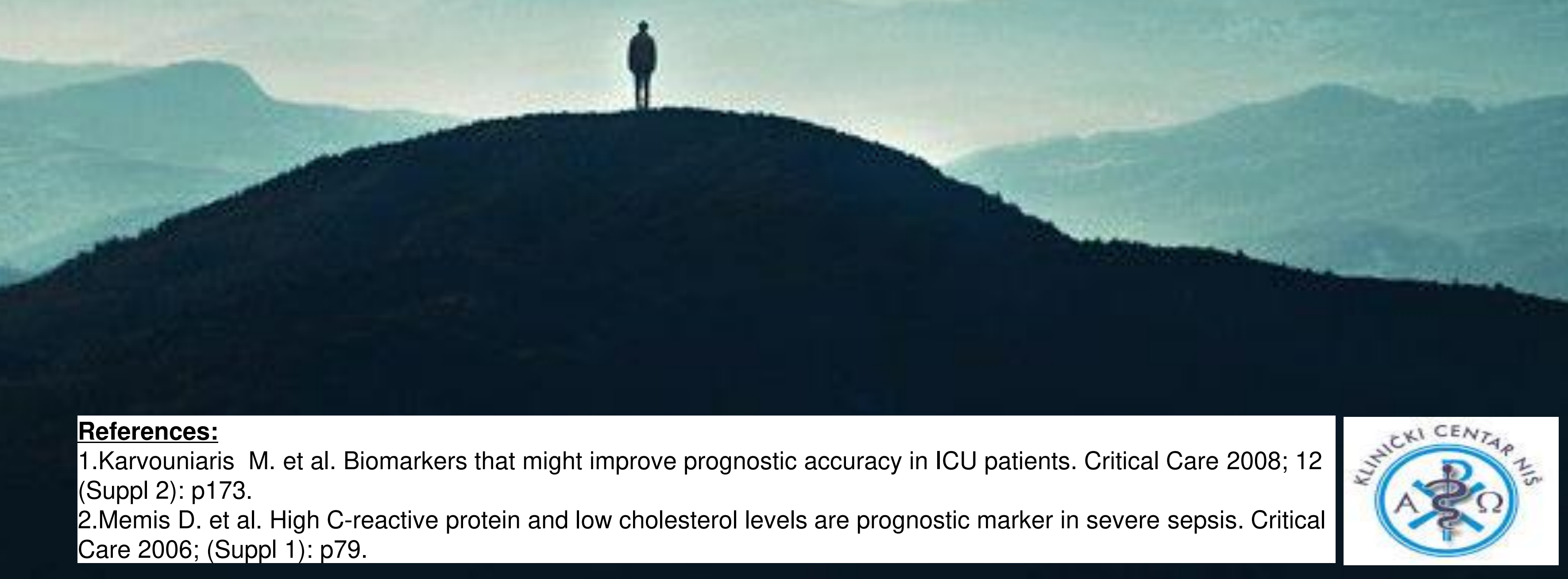

